\title{
Evaluation of factors associated with psychiatric patient dropout at a university outpatient clinic in Japan
}

\author{
Atsumi Minamisawa ${ }^{1}$ \\ Jin Narumoto' \\ Isao Yokota ${ }^{2}$ \\ Kenji Fukui' \\ 'Department of Psychiatry, \\ ${ }^{2}$ Department of Biostatistics, \\ Graduate School of Medical Science, \\ Kyoto Prefectural University of \\ Medicine, Kyoto, Japan
}

This article was published in the following Dove Press journal:

Patient Preference and Adherence

20 September 2016

Number of times this article has been viewed

Background: Patient dropout from treatment can lead to a deterioration in clinical condition, thereby increasing the need for more intensive therapy that incurs substantial social and economic losses. The aim of this study was to identify factors related to psychiatric patient dropout at a university outpatient clinic in Japan.

Methods: We retrospectively examined the medical charts of new psychiatric patients who were diagnosed with either a mood disorder (International Classification of Diseases, 10th revision, code: F3) or an anxiety disorder (F4) in the outpatient clinic at Kyoto Prefectural University of Medicine Hospital in Kyoto, Japan, between April 2010 and March 2013. The baseline characteristics of the patients (age, sex, Global Assessment of Functioning score, Clinical Global Impression-Severity of Illness score, education, occupation, marital status, duration of treatment, and prior treatment history), treating psychiatrist experience in years, and sex concordance between the patients and their treating psychiatrists were analyzed using Cox regression models.

Results: From among 1,626 eligible new patients during the study period, 532 patients were enrolled in the study (F3: $\mathrm{n}=176 ; \mathrm{F} 4$ : $\mathrm{n}=356$ ). The dropout rate was $35.7 \%$, which was similar to that of previous studies. Higher educational level, being married, and lower Global Assessment of Functioning scores were associated with a lower dropout rate. Although psychiatrist experience was not significantly associated with patient dropout in the multivariate analysis, patients treated by less experienced psychiatrists had a higher hazard ratio for dropout (1.31; 95\% confidence interval: 0.94-1.85).

Conclusion: In order to reduce the dropout rate, special focus should be placed on patients with the factors identified in this study, and young psychiatrists should undergo further education to foster adherence.

Keywords: patient dropout, psychiatry, outpatient care, mood disorders, anxiety disorders

\section{Introduction}

Patient dropout from treatment can cause a deterioration in clinical condition, resulting in the need for more intensive therapy that incurs higher social and economic losses. ${ }^{1-3}$ Previously reported dropout rates in patients with mental disorders have ranged from $20 \%$ to $82 \%$, and many risk factors have been identified (including patient age, socioeconomic status, educational level, and treating physician characteristics) for various definitions of dropout and clinical settings in different countries. ${ }^{2-10}$

Among the mental disorders, patient dropout in individuals with mood and anxiety disorders has drawn special attention due to the relatively high disease prevalence and impact on patient function. ${ }^{11-14}$ The dropout rates in patients with mood disorders have
Correspondence: Atsumi Minamisawa Department of Psychiatry, Graduate School of Medical Science, Kyoto Prefectural University of Medicine, 465 Kajii-cho, Kawaramachi Hirokoji Kamigyo-ku, Kyoto City, Kyoto 602-8566, Japan

Tel +8I 75 25। 56I2

Fax +81752515839

Email aminami@koto.kpu-m.ac.jp 
been reported to be $20 \%-60 \%$ in those undergoing pharmacological therapy and psychotherapy ${ }^{15,16}$ and $10.3 \%-57 \%$ in patients with anxiety disorders. ${ }^{12}$ However, the majority of these studies were conducted in the US, Canada, and Europe, which may differ from those conducted in Japan in terms of disease prevalence for mental disorders, cultural background, national health insurance systems, and psychiatrist training programs. ${ }^{17-24}$ The 12-month prevalence of mood disorders and anxiety disorders in Japan were reported to be $2.3 \%$ and $4.9 \%$, respectively; these prevalences were lower than those reported for the US and Europe, but similar to that reported for People's Republic of China. ${ }^{14,18-20}$ With regard to the cultural aspect of addressing mental disorders, a previous survey found that $11.5 \%$ of the Japanese population feels uncomfortable in talking about themselves to mental health care professionals, and $49.5 \%$ would feel embarrassed if their friends were to find out that they had visited mental health care professionals. ${ }^{21}$

As a possible consequence of these cultural barriers, the proportion of Japanese people who seek mental health care services is lower than in other high-income countries. ${ }^{22}$ Furthermore, the help-seeking pattern of Japanese patients differs from those in the Western countries in terms of sex and age: individuals who are male and younger are more likely to utilize mental health care services in Japan. ${ }^{21}$ These distinctive features of Japanese patients may therefore require different interventions. In addition, uninsured patients in the US are more likely to drop out from treatment, ${ }^{5}$ but Japan's universal health insurance system means that insurance coverage would not be an issue for Japanese patients.

The training system for Japanese psychiatrists has been changing after the foundation of the psychiatric board system under the management of the Japanese Society of Psychiatry and Neurology. ${ }^{23}$ However, there has yet to be any study that examined the factors related to patient dropout in a training institute for young psychiatrists in Japan. The aim of this study was to identify factors related to the dropout of outpatients being treated for mood disorders and anxiety disorders at a university outpatient clinic in order to reduce dropouts from treatment.

\section{Patients and methods Setting}

Kyoto Prefectural University of Medicine (KPUM) is a tertiary care teaching hospital located within the urban area of Kyoto prefecture, and plays a role in educating physicians in addition to providing highly effective treatments. Because patients in Japan are permitted to seek care from any hospital without first visiting a primary care physician, patients with mental disorders may choose to be treated at a university hospital instead of a psychiatric hospital for a variety of reasons, such as convenience of location and access, avoidance of the stigma of psychiatric hospitals, and expectations of intensive treatment options for difficult conditions that may not be available at general hospitals and private clinics. Furthermore, some patients may not actually wish to be treated at the university hospital, but instead seek second opinions, medical certificates, or medical examinations. All patients who visit KPUM for a first-time psychiatric visit and patients who are suspected as having complicated problems or severe symptoms are seen by more experienced psychiatrists.

\section{Subjects}

In this study, patients diagnosed as having mood disorders (International Classification of Diseases, 10th revision, code: F3) and anxiety disorders (F4) were included in the study if they were aged 18 years or older and had visited KPUM for the first time between April 2010 and March $2013 .{ }^{24} \mathrm{~F} 3$ disorders are mood (affective) disorders, which include manic episodes, bipolar affective disorder, depressive episodes, recurrent depressive disorder, persistent mood disorder, and other mood disorders. F4 disorders are neurotic, stress-related, and somatoform disorders, which include phobic anxiety disorders, other anxiety disorders, obsessive compulsive disorder, reaction to severe stress and adjustment disorders, dissociative (conversion) disorders, somatoform disorders, and other neurotic disorders. Patients who had visited KPUM for nontreatment purposes (eg, to obtain a second opinion, medical certificate, or medical examination) were excluded from analysis; in addition, we also excluded patients who were diagnosed as not needing treatment for more than 2 months. Psychosocial therapies, including education and supportive interventions, were provided in combination with pharmacotherapy in daily practice, but patients who received cognitive behavioral therapy in special settings (specialized outpatient clinic in Figure 1) were excluded because the time and frequency of their hospital visits substantially differ from those of other patients. Patient selection is summarized in Figure 1.

From each patient's medical chart, we collected information on patient age, sex, marital status, occupation, and educational level. Educational level was categorized into "high" ( $>16$ years of formal education, indicating university graduate level) and "low" ( $\leq 16$ years of formal education). The Clinical Global Impression-Severity of Illness (CGI-S) scale and the Global Assessment of Functioning (GAF) scale 

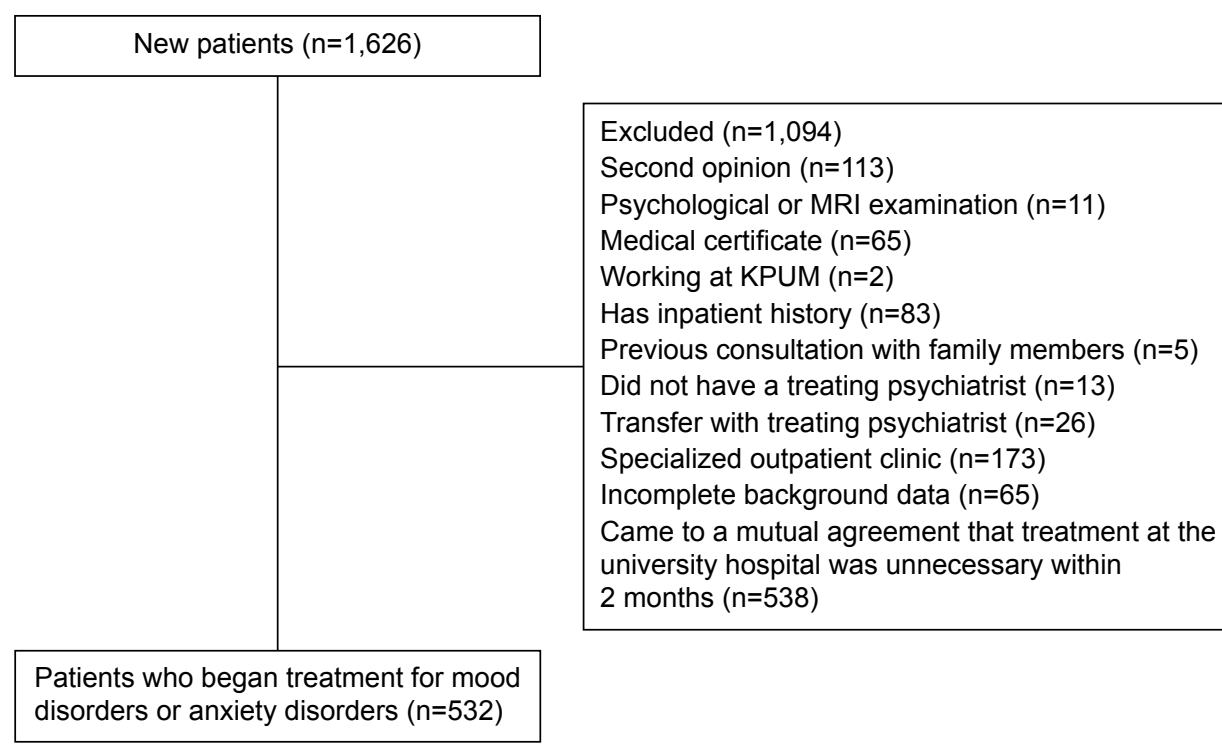

Figure I Patient selection.

Abbreviations: MRI, magnetic resonance imaging; KPUM, Kyoto Prefectural University of Medicine.

were also used to assess the overall psychiatric condition of each patient. ${ }^{25,26}$ The CGI-S scale assesses the level of mental illness using a seven-point scale (ranging from " $1=$ normal, not at all ill" to "7= among the most extremely ill"). The GAF scale assesses patient function from the aspects of psychological, social, and occupational function on the hypothetical continuum of mental health illness from 1 to 100 (ranging from " $1-10=$ Persistent danger of severely hurting self or others or persistent to maintain minimal personal hygiene or serious suicidal act with clear expectation of death" to " $91-100=$ No symptoms. Superior functioning in wide range of activities, life's problems never seem to get out of hand, is sought out by others because of his or her many positive qualities"). One of the authors (AM) analyzed the medical charts of all subjects to determine CGI-S and GAF scores. Although both these scores are indicative of patient function, the CGI-S requires the rater to consider their total clinical experience with the particular population.

In addition, we collected information on the treating psychiatrists' sex, marital status, and years of practice as a psychiatrist. This study was approved by the KPUM Research Ethics Committee. Informed consent for the patients was waived because all data were collected directly from the medical charts by the treating psychiatrist; also, information on this study was provided at the hospital noticeboard and website to allow patients to contact the authors if they refused to participate in the study. Informed consent was obtained from all the participating psychiatrists. The KPUM Research Ethics Committee approved the consent process.

\section{Definition of patient dropout}

In this study, we defined dropout patients as those who had failed to return to the hospital for the next appointment without their psychiatrist's consent, and did not come back to continue treatment for 90 days based on the definition proposed by Tansella et al. ${ }^{27}$

\section{Statistical analyses}

Kaplan-Meier analysis was conducted to show the proportion of patients continuing treatment among all patients included in the study. Univariate and multivariate Cox regression models were developed to analyze the strength of factors affecting the time to dropping out of treatment. The length of therapy in months was set as the dependent variable in the regression model, and the independent variables included patient age, sex, diagnosis, educational level, occupation, marital status, GAF score, CGI-S score, and previous treatment; in addition, psychiatrists' age, sex, marital status, experience in years, and patient-psychiatrist sex concordance were also included as independent variables. Data for patients who experienced a change in their treating psychiatrist were censored. All statistical analyses were conducted using SPSS version 22.0 (SPSS Inc., Chicago, IL, USA), and a two-sided $P$-value $<0.05$ was considered significant.

\section{Results \\ Demographic and clinical characteristics}

During the study period, a total of 1,626 patients with either an F3 or F4 diagnosis visited the outpatient clinic, 
and 532 subjects (F3: $n=176 ; F 4: n=356)$ met the inclusion criteria. These patients were treated by a total of 29 psychiatrists. Among these, 21 psychiatrists were males and six psychiatrists had 10 years or more of experience. The demographic characteristics are presented in Table 1. A total

Table I Demographic characteristics of the patients and treating psychiatrists

\begin{tabular}{|c|c|}
\hline Factor & $\begin{array}{l}\text { Number } \\
\text { of patients }\end{array}$ \\
\hline \multicolumn{2}{|l|}{ Patients } \\
\hline \multicolumn{2}{|l|}{ Sex } \\
\hline Male & 224 \\
\hline Female & 308 \\
\hline \multicolumn{2}{|l|}{ Age } \\
\hline 18-25 years & 106 \\
\hline $26-45$ years & 227 \\
\hline 46-65 years & $14 \mid$ \\
\hline$\geq 66$ years & 58 \\
\hline \multicolumn{2}{|l|}{ Diagnosis } \\
\hline Mood disorders ${ }^{\mathrm{a}}$ & 176 \\
\hline Anxiety disorders ${ }^{\mathrm{b}}$ & 356 \\
\hline \multicolumn{2}{|l|}{ Education } \\
\hline Low & 349 \\
\hline High & 183 \\
\hline \multicolumn{2}{|l|}{ Occupation } \\
\hline None & 86 \\
\hline Housewife/student & 184 \\
\hline Employed & 262 \\
\hline \multicolumn{2}{|l|}{ Marital status } \\
\hline Married & 224 \\
\hline Divorced/widowed & 83 \\
\hline Single & 225 \\
\hline \multicolumn{2}{|l|}{ GAF score } \\
\hline$\leq 50$ & 148 \\
\hline $5 I-60$ & 248 \\
\hline$\geq 61$ & 136 \\
\hline \multicolumn{2}{|l|}{ CGI-S score } \\
\hline $\mathrm{I}-2$ & 51 \\
\hline $3-4$ & 375 \\
\hline $5-6$ & 106 \\
\hline \multicolumn{2}{|l|}{ Previous treatment } \\
\hline No & 202 \\
\hline Yes & 330 \\
\hline \multicolumn{2}{|l|}{ Psychiatrists } \\
\hline \multicolumn{2}{|l|}{ Sex } \\
\hline Male & 429 \\
\hline Female & 103 \\
\hline \multicolumn{2}{|l|}{ Marital status } \\
\hline Married & 389 \\
\hline Divorced/widowed & 51 \\
\hline Single & 92 \\
\hline \multicolumn{2}{|l|}{ Experience in years } \\
\hline$<10$ years & 328 \\
\hline$\geq 10$ years & 204 \\
\hline \multicolumn{2}{|l|}{ Sex concordance } \\
\hline Concordant & 246 \\
\hline Discordant & 286 \\
\hline
\end{tabular}

Notes: aldentified using International Classification of Diseases, 10th revision (ICD-I0), code F3; bidentified using ICD-10 code F4.

Abbreviations: CGI-S, Clinical Global Impression-Severity of IIlness; GAF, Global Assessment of Functioning. of 190 patients (35.7\%) stopped coming to the clinic without consent from their treating psychiatrist. The dropout rates of patients diagnosed with F3 and F4 were $33.5 \%$ and $36.8 \%$, respectively, and the demographic characteristics according to diagnosis are presented in Table 2.

Table 2 Difference in demographic characteristics between continuing and dropout patients

\begin{tabular}{|c|c|c|}
\hline Factor & $\begin{array}{l}\text { Continuing } \\
(n=342)\end{array}$ & $\begin{array}{l}\text { Dropout } \\
(n=190)(\%)^{a}\end{array}$ \\
\hline \multicolumn{3}{|l|}{ Patients } \\
\hline \multicolumn{3}{|l|}{ Sex } \\
\hline Male & 144 & $80(15.0)$ \\
\hline Female & 198 & $110(20.7)$ \\
\hline \multicolumn{3}{|l|}{ Age } \\
\hline $18-25$ years & 56 & $50(9.4)$ \\
\hline $26-45$ years & 148 & $79(14.8)$ \\
\hline $46-65$ years & 100 & $4 \mid(7.7)$ \\
\hline$\geq 66$ years & 38 & $20(3.8)$ \\
\hline \multicolumn{3}{|l|}{ Diagnosis } \\
\hline Mood disorders & 117 & 59 (II.I) \\
\hline Anxiety disorders & 225 & $13 \mid(24.6)$ \\
\hline \multicolumn{3}{|l|}{ Education } \\
\hline Low & 207 & I42 (26.7) \\
\hline High & 135 & $48(9.0)$ \\
\hline \multicolumn{3}{|l|}{ Occupation } \\
\hline None & 59 & $27(5.1)$ \\
\hline Housewife/student & 114 & $70(13.2)$ \\
\hline Employed & 169 & $93(17.5)$ \\
\hline \multicolumn{3}{|l|}{ Marital status } \\
\hline Currently married & 154 & $70(13.2)$ \\
\hline Divorced/widowed & 45 & $38(7.1)$ \\
\hline Single & 143 & $82(15.4)$ \\
\hline \multicolumn{3}{|l|}{ GAF score } \\
\hline$\leq 50$ & 97 & $51(9.6)$ \\
\hline $5 I-60$ & 168 & $80(15.0)$ \\
\hline$\geq 61$ & 77 & $59(11.1)$ \\
\hline \multicolumn{3}{|l|}{ CGI-S score } \\
\hline $\mathrm{I}-2$ & 29 & $22(4.1)$ \\
\hline $3-4$ & 242 & $133(25.0)$ \\
\hline $5-6$ & 71 & $35(6.6)$ \\
\hline \multicolumn{3}{|l|}{ Previous treatment } \\
\hline No & 128 & 74 (13.9) \\
\hline Yes & 214 & $116(21.8)$ \\
\hline \multicolumn{3}{|l|}{ Psychiatrists } \\
\hline \multicolumn{3}{|l|}{ Sex } \\
\hline Male & 284 & I 45 (27.3) \\
\hline Female & 58 & $45(8.5)$ \\
\hline \multicolumn{3}{|l|}{ Marital status } \\
\hline Married & 261 & $128(24.1)$ \\
\hline Divorced/widowed & 26 & $25(4.7)$ \\
\hline Single & 55 & $37(7.0)$ \\
\hline \multicolumn{3}{|l|}{ Experience in years } \\
\hline$<10$ years & 199 & $129(24.2)$ \\
\hline$\geq 10$ years & 143 & $61(11.5)$ \\
\hline \multicolumn{3}{|l|}{ Sex concordance } \\
\hline Concordant & 165 & 81 (I5.2) \\
\hline Discordant & 177 & $109(20.5)$ \\
\hline
\end{tabular}

Note: ${ }^{\mathrm{a}}$ The denominator for this percentage is the total number of patients in the study sample $(n=532)$.

Abbreviations: CGI-S, Clinical Global Impression-Severity of Illness; GAF, Global Assessment of Functioning. 


\section{Factors related to patient dropout}

Table 3 shows the results of the Cox regression analyses. The univariate analyses identified educational level, GAF score, and psychiatrist experience to be significantly associated with patient dropout. In the multivariate analysis, patient age, educational level, marital status, and GAF score were found to be significantly associated with patient dropout. Although psychiatrist experience was not significantly associated with patient dropout in the multivariate analysis, the hazard ratio was 1.31 (95\% confidence interval: $0.94-1.85)$ in patients

Table 3 Results of univariate and multivariate Cox regression analyses of factors associated with patient dropout

\begin{tabular}{|c|c|c|c|c|c|c|}
\hline \multirow[t]{2}{*}{ Factor } & \multicolumn{3}{|c|}{ Univariate } & \multicolumn{3}{|c|}{ Multivariate } \\
\hline & HR & $95 \% \mathrm{Cl}$ & $P$-value & HR & $95 \% \mathrm{Cl}$ & $P$-value \\
\hline \multicolumn{7}{|l|}{ Patients } \\
\hline \multicolumn{7}{|l|}{ Sex } \\
\hline Male & I.0I & $(0.76-I .35)$ & 0.93 & $\mathrm{I} .14$ & $(0.80-I .6 I)$ & 0.51 \\
\hline Female & Reference & & & & & \\
\hline \multicolumn{7}{|l|}{ Age } \\
\hline $18-25$ years & 1.38 & $(0.82-2.32)$ & 0.22 & 1.82 & $(1.01-3.46)$ & $<0.05$ \\
\hline $26-45$ years & 0.92 & $(0.56-1.50)$ & 0.73 & 1.28 & $(0.77-2.26)$ & 0.32 \\
\hline $46-65$ years & 0.76 & $(0.44-1.30)$ & 0.31 & 0.90 & $(0.54-I .58)$ & 0.77 \\
\hline$\geq 66$ years & Reference & & & & & \\
\hline \multicolumn{7}{|l|}{ Diagnosis } \\
\hline Mood disorders & 0.86 & $(0.64-I .18)$ & 0.35 & 0.83 & $(0.60-1.14)$ & 0.24 \\
\hline Anxiety disorders & Reference & & & & & \\
\hline \multicolumn{7}{|l|}{ Education } \\
\hline Low & 1.72 & $(1.24-2.39)$ & $<0.01$ & $\mathrm{I} .64$ & $(I .|7-2.3|)$ & $<0.01$ \\
\hline High & Reference & & & & & \\
\hline \multicolumn{7}{|l|}{ Occupation } \\
\hline None & 0.83 & $(0.54-\mathrm{I} .28)$ & 0.40 & 0.66 & $(0.42-1.05)$ & 0.08 \\
\hline Housewife/student & 1.09 & $(0.80-1.48)$ & 0.61 & 0.67 & $(0.60-1.25)$ & 0.44 \\
\hline Employed & Reference & & & & & \\
\hline \multicolumn{7}{|l|}{ Marital status } \\
\hline Married & 0.86 & $(0.62-1.18)$ & 0.34 & 1.12 & $(0.75-1.67)$ & 0.60 \\
\hline Divorced/widowed & 1.37 & $(0.93-2.01)$ & 0.11 & 1.58 & $(1.03-2.43)$ & $<0.05$ \\
\hline Single & Reference & & & & & \\
\hline \multicolumn{7}{|l|}{ GAF } \\
\hline$\leq 50$ & 0.72 & $(0.50-1.05)$ & 0.09 & 0.76 & $(0.43-I .34)$ & 0.34 \\
\hline $51-60$ & 0.66 & $(0.47-0.93)$ & $<0.05$ & 0.63 & $(0.42-0.94)$ & $<0.05$ \\
\hline $61-100$ & Reference & & & & & \\
\hline \multicolumn{7}{|l|}{ CGI-S } \\
\hline $\mathrm{I}-2$ & 1.55 & $(0.91-2.65)$ & 0.11 & 2.01 & $(0.57-2.70)$ & 0.60 \\
\hline $3-4$ & 1.10 & $(0.76-1.60)$ & 0.60 & 1.07 & $(0.69-2.13)$ & 0.50 \\
\hline $5-6$ & Reference & & & & & \\
\hline \multicolumn{7}{|l|}{ Previous treatment } \\
\hline Yes & 1.03 & $(0.77-I .38)$ & 0.85 & 0.96 & $(0.7 I-I .29)$ & 0.77 \\
\hline No & Reference & & & & & \\
\hline \multicolumn{7}{|l|}{ Psychiatrists } \\
\hline \multicolumn{7}{|l|}{ Sex } \\
\hline Male & 0.72 & $(0.52-1.01)$ & 0.06 & 0.80 & $(0.57-I .12)$ & 0.50 \\
\hline Female & Reference & & & & & \\
\hline \multicolumn{7}{|l|}{ Marital status } \\
\hline Married & 0.79 & $(0.55-I .14)$ & 0.21 & 0.90 & $(0.60-1.36)$ & 0.62 \\
\hline Divorced/widowed & 1.23 & $(0.74-2.04)$ & 0.43 & I.I5 & $(0.67-1.95)$ & 0.62 \\
\hline Single & Reference & & & & & \\
\hline \multicolumn{7}{|l|}{ Experience in years } \\
\hline$<10$ years & $\mathrm{I} .44$ & $(1.06-1.96)$ & $<0.05$ & I.31 & $(0.94-1.85)$ & 0.11 \\
\hline$\geq 10$ years & Reference & & & & & \\
\hline \multicolumn{7}{|l|}{ Sex concordance } \\
\hline Concordant & 0.83 & $(0.63-I . I I)$ & 0.21 & 0.73 & $(0.52-1.02)$ & 0.07 \\
\hline Discordant & Reference & & & & & \\
\hline
\end{tabular}

Abbreviations: CGI-S, Clinical Global Impression-Severity of Illness; GAF, Global Assessment of Functioning; Cl, confidence interval; HR, hazard ratio. 


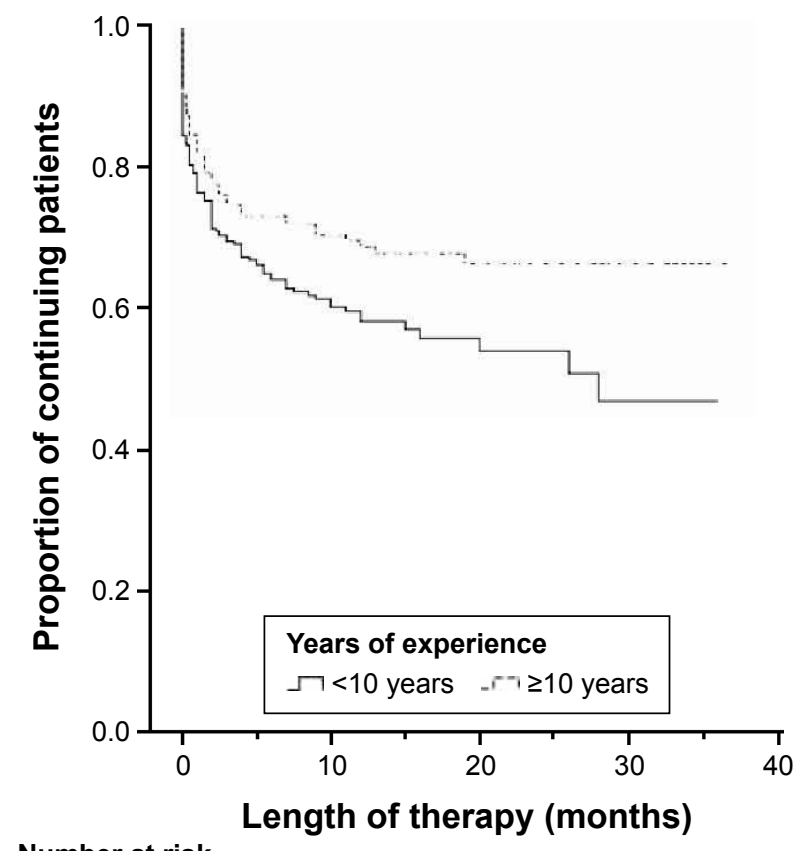

Number at risk

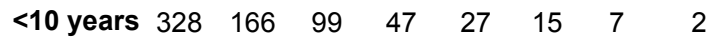

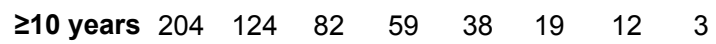

Figure 2 Proportion of continuing patients according to the treating psychiatrists' experience in years.

treated by psychiatrists with fewer than 10 years of experience. Similarly, the Kaplan-Meier curves in Figure 2 show that patients treated by less experienced psychiatrists had a higher rate of dropout than those treated by psychiatrists with 10 years or more of experience.

As shown in Table 4, the factors associated with patient dropout differed between the two diagnoses. Patients in the F3 group, with a higher educational level, were less likely to drop out of treatment, but more likely to drop out if they were divorced or widowed (relative to being single or married). Patients with an F4 diagnosis were more likely to drop out if they were young (18-25 years) or had a GAF score of 51-60. In addition, patients with an F4 diagnosis and were the opposite sex as their treating psychiatrist were more likely to drop out of treatment.

\section{Discussion}

The overall dropout rate was $35.7 \%$, which was within the range previously reported in various clinical settings. ${ }^{2-10}$ In this study, we identified patient, psychiatrist, and interaction factors associated with patient dropout in individuals treated for mood disorders and anxiety disorders at a university outpatient clinic in Japan. Patient factors associated with dropout in all subjects were of younger age (18-25 years), lower educational level, being widowed or divorced, and high
GAF scores. Lower educational level and being widowed or divorced were associated with dropout in the F3 group, whereas younger age, high GAF scores, and patientphysician sex discordance were associated with dropout in the F4 group. These findings are expected to contribute to improving our hospital's practice and education to reduce patient dropout.

Our study found that high GAF scores were associated with a higher dropout rate, which corroborates the findings of a previous report by Rossi et al. ${ }^{2} \mathrm{We}$ can assume that higherfunctioning patients are more capable of independently solving their problems, and are therefore more likely to decide to cease treatment. Educational level was also identified as a determinant of patient dropout in all subjects and the F3 group, which supports the findings of previous studies. ${ }^{2,4,9,28}$ Patients with mood disorders are recommended to continue medication even after the resolution of symptoms to prevent relapse, and a certain degree of health care literacy may allow patients to adhere to treatments even in the absence of symptoms. This suggests that patients with lower educational levels who suffer from mood disorders may benefit from additional specialized psychoeducation about their treatments. Furthermore, the youngest age group and a GAF score of 51-60 increased the likelihood of dropping out in the $\mathrm{F} 4$ group. A recent review on anxiety disorders by Santana and Fontenelle showed that only one study out of 16 reported a relationship between age and patient dropout, ${ }^{12}$ whereas other studies have reported an association between younger patients and patient dropout. ${ }^{5,6,9}$ In addition, the review by Santana and Fontenelle found that two studies reported a positive relationship between disease severity and adherence to treatment, but the results were inconsistent. ${ }^{12}$

Divorced or widowed patients were also significantly associated with higher patient dropout. Social solitude has been reported to be a determinant of dropout in previous studies, ${ }^{4,6}$ and it can be assumed that patients without family support would have difficulties in daily life, including making frequent visits to hospitals.

Psychiatrist experience was identified as a factor related to patient dropout in the univariate analysis. This is consistent with our previous findings that patients' trust was higher in psychiatrists who had 10 years or more of experience. ${ }^{29} \mathrm{It}$ is possible that more experienced psychiatrists may interact differently with patients. It has also been reported that residents tend to take a long time to build a relationship with patients, whereas attending physicians focus more on biomedically related data gathering, counseling, and 
Table 4 Results of multivariate Cox regression analyses of factors associated with patient dropout according to diagnosis

\begin{tabular}{|c|c|c|c|c|c|c|}
\hline \multirow[t]{2}{*}{ Factor } & \multicolumn{3}{|c|}{ Mood disorders } & \multicolumn{3}{|c|}{ Anxiety disorders } \\
\hline & HR & $95 \% \mathrm{Cl}$ & $P$-value & HR & $95 \% \mathrm{Cl}$ & $P$-value \\
\hline \multicolumn{7}{|l|}{ Patients } \\
\hline \multicolumn{7}{|l|}{ Sex } \\
\hline Male & 1.42 & $(0.73-2.79)$ & 0.31 & 1.16 & $(0.76-1.76)$ & 0.50 \\
\hline Female & Reference & & & & & \\
\hline \multicolumn{7}{|l|}{ Age } \\
\hline $18-25$ years & 1.64 & $(0.52-5.15)$ & 0.39 & 2.33 & $(1.09-4.97)$ & $<0.05$ \\
\hline $26-45$ years & 0.69 & $(0.26-1.85)$ & 0.46 & 1.45 & $(0.74-2.84)$ & 0.27 \\
\hline $46-65$ years & 0.85 & $(0.34-2.11)$ & 0.72 & 0.96 & $(0.48-1.91)$ & 0.90 \\
\hline$\geq 66$ years & Reference & & & & & \\
\hline \multicolumn{7}{|l|}{ Education } \\
\hline Low & 2.48 & $(1.24-2.39)$ & $<0.05$ & 1.41 & $(0.94-2.11)$ & 0.10 \\
\hline High & Reference & & & & & \\
\hline \multicolumn{7}{|l|}{ Occupation } \\
\hline None & 0.56 & $(0.24-\mid .3 I)$ & 0.18 & 0.74 & $(0.42-1.29)$ & 0.28 \\
\hline Housewife/student & 0.48 & $(0.20-1.14)$ & 0.10 & 1.05 & $(0.69-1.60)$ & 0.83 \\
\hline Employed & Reference & & & & & \\
\hline \multicolumn{7}{|l|}{ Marital status } \\
\hline Married & 1.25 & $(0.59-2.68)$ & 0.56 & 1.07 & $(0.66-1.73)$ & 0.79 \\
\hline Divorced/widowed & 2.23 & $(1.01-4.89)$ & $<0.05$ & 1.57 & $(0.90-2.74)$ & 0.12 \\
\hline Single & Reference & & & & & \\
\hline \multicolumn{7}{|l|}{ GAF } \\
\hline$\leq 50$ & 1.32 & $(0.49-3.56)$ & 0.59 & 0.59 & $(0.43-1.34)$ & 0.17 \\
\hline $5 I-60$ & 1.37 & $(0.62-3.03)$ & 0.44 & 0.46 & $(0.42-0.94)$ & $<0.05$ \\
\hline $61-100$ & Reference & & & & & \\
\hline \multicolumn{7}{|l|}{ CGI-S } \\
\hline $1-2$ & 0.41 & $(0.39-4.34)$ & 0.46 & 1.26 & $(0.49-3.23)$ & 0.63 \\
\hline $3-4$ & 1.68 & $(0.6 \mathrm{I}-4.60)$ & 0.32 & 1.09 & $(0.52-2.29)$ & 0.82 \\
\hline $5-6$ & Reference & & & & & \\
\hline \multicolumn{7}{|l|}{ Previous treatment } \\
\hline Yes & 0.78 & $(0.43-1.43)$ & 0.42 & 0.90 & $(0.6 I-I .3 I)$ & 0.57 \\
\hline No & Reference & & & & & \\
\hline \multicolumn{7}{|l|}{ Psychiatrist } \\
\hline \multicolumn{7}{|l|}{ Sex } \\
\hline Male & 0.84 & $(0.39-1.83)$ & 0.67 & 0.77 & $(0.47-1.25)$ & 0.29 \\
\hline Female & Reference & & & & & \\
\hline \multicolumn{7}{|l|}{ Marital status } \\
\hline Married & 1.46 & $(0.56-3.82)$ & 0.44 & 0.82 & $(0.5 I-I .3 I)$ & 0.40 \\
\hline Divorced/widowed & 1.34 & $(0.49-3.67)$ & 0.57 & 1.29 & $(0.66-2.54)$ & 0.46 \\
\hline Single & Reference & & & & & \\
\hline \multicolumn{7}{|l|}{ Experience in years } \\
\hline$<10$ years & 1.32 & $(0.69-2.54)$ & 0.40 & 1.31 & $(0.87-1.98)$ & 0.20 \\
\hline$\geq 10$ years & Reference & & & & & \\
\hline \multicolumn{7}{|l|}{ Sex concordance } \\
\hline Concordant & 0.65 & $(0.35-1.22)$ & 0.18 & 0.64 & $(0.42-0.97)$ & $<0.05$ \\
\hline Discordant & Reference & & & & & \\
\hline
\end{tabular}

Abbreviations: CGI-S, Clinical Global Impression-Severity of Illness; GAF, Global Assessment of Functioning; Cl, confidence interval; HR, hazard ratio.

patient education..$^{30}$ Further study is required to identify the factors that influence patient dropout in relation to psychiatrist experience. However, a significant relationship was not detected between psychiatrist experience and patient dropout in the multivariate analysis. A possible reason for this disparity in observations is that the sex of the treating psychiatrist may be a confounding factor, and that all the experienced psychiatrists at KPUM during the study period were males. Therefore, further studies comprising several hospitals and clinics with a more even distribution in psychiatrist sex should be conducted to elucidate the relationship between psychiatrist experience and patient dropout. 
Sex discordance was also associated with higher patient dropout in the F4 group. A previous review of the effects of sex on doctor-patient communication by Sandhu et al showed that dyads comprising female doctors and female patients led to the most patient-centered communication and longer consultations. ${ }^{31}$ Further study is needed to see the causal relationship between the sex concordance and the dropout.

\section{Limitations}

There are several limitations in our study. First, this was a retrospective study and all data were obtained solely from medical charts. When compared with studies that use direct or prospective methods, such as interviews or sending questionnaires, the data we obtained may be biased. Also, we were unable to obtain precise information on the psychiatric care received before visiting KPUM, physicians' attitudes, or the involvement of patients and their families in decision making, which are important factors to consider in the issue of patient dropout. Moreover, our data did not allow us to ascertain the type of treatment or psychotropic medications prescribed before visiting KPUM, or whether dropout patients continued treatment in other hospitals. Next, this study focused only on patients with mood disorders and anxiety disorders. However, a study by Ozaki et al showed that the dropout rate in a Japanese hospital was similar among all psychiatric diagnoses. ${ }^{32}$ Finally, we were unable to identify the specific factors associated with more experienced physicians that led to lower dropout rates. Future prospective studies should address if there is a causal relationship between physician experience and dropout rates.

\section{Conclusion}

In summary, several factors were found to be associated with patient dropout. In order to reduce dropout rates, treatment approaches in the clinical setting should be tailored according to patient characteristics. Also, it is important to educate young psychiatrists in focusing on building an effective patient-doctor relationship to foster adherence to treatment.

\section{Disclosure}

The authors report no conflicts of interest in this work.

\section{References}

1. Stone CA, Palmer JH, Saxby PJ, Devaraj VS. Reducing non-attendance at outpatient clinics. J R Soc Med. 1999;92(3):114-118.

2. Rossi A, Amaddeo F, Sandri M, Marsilio A, Bianco M, Tansella M. What happens to patients seen only once by psychiatric services? Findings from a follow-up study. Psychiatry Res. 2008;157(1-3):53-65.
3. Killaspy H, Banerjee S, King M, Lloyd M. Prospective controlled study of psychiatric out-patient non-attendance. Characteristics and outcome. Br J Psychiatry. 2000;176:160-165.

4. Baekeland F, Lundwall L. Dropping out of treatment: a critical review. Psychol Bull. 1975;82(5):738-783.

5. Edlund MJ, Wang PS, Berglund PA, Katz SJ, Lin E, Kessler RC. Dropping out of mental health treatment: patterns and predictors among epidemiological survey respondents in the United States and Ontario. Am J Psychiatry. 2002;159(5):845-851.

6. Rossi A, Amaddeo F, Bisoffi G, Ruggeri M, Thornicroft G, Tansella M. Dropping out of care: inappropriate terminations of contact with community-based psychiatric services. Br J Psychiatry. 2002;181: 331-338.

7. Swett C Jr, Noones J. Factors associated with premature termination from outpatient treatment. Hosp Community Psychiatry. 1989;40(9): 947-951.

8. Morlino M, Martucci G, Musella V, Bolzan M, de Girolamo G. Patients dropping out of treatment in Italy. Acta Psychiatr Scand. 1995;92(1): $1-6$.

9. Chen A. Noncompliance in community psychiatry: a review of clinical interventions. Hosp Community Psychiatry. 1991;42(3):282-287.

10. Wells JE, Browne MO, Aguilar-Gaxiola S, et al. Drop out from outpatient mental healthcare in the World Health Organization's World Mental Health Survey initiative. Br J Psychiatry. 2013;202(1):42-49.

11. Kessler RC, Berglund P, Demler O, et al. The epidemiology of major depressive disorder: results from the National Comorbidity Survey Replication (NCS-R). JAMA. 2003;289(23):3095-3105.

12. Santana L, Fontenelle LF. A review of studies concerning treatment adherence of patients with anxiety disorders. Patient Prefer Adherence. 2011;5:427-439.

13. Sado M, Yamauchi K, Kawakami N, et al. Cost of depression among adults in Japan in 2005. Psychiatry Clin Neurosci. 2011;65(5): 442-450.

14. Ishikawa H, Kawakami N, Kessler RC. Lifetime and 12-month prevalence, severity and unmet need for treatment of common mental disorders in Japan: results from the final dataset of World Mental Health Japan Survey. Epidemiol Psychiatr Sci. 2016;25(3):217-229.

15. Demyttenaere K, Enzlin P, Dewe W, et al. Compliance with antidepressants in a primary care setting, 1: beyond lack of efficacy and adverse events. J Clin Psychiatry. 2001;62(Suppl 22):30-33.

16. Moon E, Chang JS, Kim MY, et al. Dropout rate and associated factors in patients with bipolar disorders. J Affect Disord. 2012;141(1): $47-54$.

17. Iryou hosho ni tsuiteno kokusaikankeishiryo. [The data on medical insurance system from international data]. Ministry of Health, Labour and Welfare; 2012. Japanese. Available from: http://www.mhlw.go.jp/ stf/seisakunitsuite/bunya/kenkou_iryou/iryouhoken/iryouhoken11/. Accessed August 18, 2016.

18. Kessler RC, Chiu WT, Demler O, Merikangas KR, Walters EE. Prevalence, severity, and comorbidity of 12-month DSM-IV disorders in the National Comorbidity Survey Replication. Arch Gen Psychiatry. 2005;62(6):617-627.

19. Alonso J, Angermeyer MC, Bernert S, et al. Prevalence of mental disorders in Europe: results from the European Study of the Epidemiology of Mental Disorders (ESEMeD) project. Acta Psychiatr Scand Suppl. 2004; (420):21-27.

20. Shen YC, Zhang MY, Huang YQ, et al. Twelve-month prevalence, severity, and unmet need for treatment of mental disorders in metropolitan China. Psychol Med. 2006;36(2):257-267.

21. Kido Y, Kawakami N; WHO World Mental Health Japan Survey Group. Sociodemographic determinants of attitudinal barriers in the use of mental health services in Japan: findings from the World Mental Health Japan Survey 2002-2006. Psychiatry Clin Neurosci. 2013; 67:101-109.

22. Wang PS, Aguilar-Gaxiola S, Alonso J, et al. Use of mental health services for anxiety, mood, and substance disorders in 17 countries in the WHO world mental health surveys. Lancet. 2007;370:841-850. 
23. Yamauchi T. [Outcomes of Psychiatric Board System under Japanese Society of Psychiatry and Neurology, and the New Board System under the Japanese Medical Speciality Board. Psychiatria st Neurologia Japonica]. 2016;118(5):287-303. Japanese.

24. World Health Organization. The ICD-10 Classification of Mental and Behavioral Disorders: Clinical Descriptions and Diagnostic Guidelines. Geneva: World Health Organization; 1992.

25. Guy W. ECDEU Assessment Manual for PsychopharmacologyRevised. Rockville, MD: US Department of Health, Education, and Welfare, Public Health Service, Alcohol, Drug Abuse, and Mental Health Administration, NIMH Psychopharmacology Research Branch, Division of Extramural Research Programs; 1976:5.

26. American Psychiatric Association. Diagnostic and Statistical Manual of Mental Disorders. 4th ed. Washington, DC: American Psychiatric Association; 1994.

27. Tansella M, Micciolo R, Biggeri A, Bisoffi G, Balestrieri M. Episodes of care for first-ever psychiatric patients. A long-term case-register evaluation in a mainly urban area. Br J Psychiatry. 1995;167(2):220-227.

28. Jellinek M. Referrals from a psychiatric emergency room: relationship of compliance to demographic and interview variables. Am J Psychiatry. 1978;135(2):209-213.
29. Minamisawa A, Suzuki T, Watanabe K, et al. Patient's trust in their psychiatrist: a cross-sectional survey. Eur Arch Psychiatry Clin Neurosci. 2011;261(8):603-608.

30. Castillo EG, Pincus HA, Wieland M, et al. Communication profiles of psychiatric residents and attending physicians in medicationmanagement appointments: a quantitative pilot study. Acad Psychiatry. 2012;36(2):96-103.

31. Sandhu H, Adams A, Singleton L, Clark-Carter D, Kidd J. The impact of gender dyads on doctor-patient communication: a systematic review. Patient Educ Couns. 2009;76(3):348-355.

32. Ozaki A, Kumakura N, Ueno T, et al. [The termination of psychiatric out-patient treatment: the second study - A statistical study about "dropout", "admission to psychiatric hospital", "suicide", and "approved termination”]. Japanese Journal of Social Psychiatry. 1984;7(1):41-52. Japanese.

\section{Publish your work in this journal}

Patient Preference and Adherence is an international, peer-reviewed, open access journal that focuses on the growing importance of patient preference and adherence throughout the therapeutic continuum. Patient satisfaction, acceptability, quality of life, compliance, persistence and their role in developing new therapeutic modalities and compounds to optimize clinical outcomes for existing disease states are major areas of interest for the journal. This journal has been accepted for indexing on PubMed Central. The manuscript management system is completely online and includes a very quick and fair peer-review system, which is all easy to use. Visit http://www. dovepress.com/testimonials.php to read real quotes from published authors.

Submit your manuscript here: http://www.dovepress.com/patient-preference-and-adherence-journal 